\section{References}

1. Choe DH, Marom EM, Ahrar K, Truong MT, Madewell JE. Pulmonary embolism of polymethyl methacrylate during percutaneous vertebroplasty and kyphoplasty. AJR Am J Roentgenol. 2004;183:1097-102.

2. Krueger A, Bliemel C, Zettl R, Ruchholtz S. Management of pulmonary cement embolism after percutaneous vertebroplasty and kyphoplasty: a systematic review of the literature. Eur Spine J. 2009;18:1257-65.
3. Blinc A, Bozic M, Vengust R, Stegnar M. Methyl-methacrylate bone cement surface does not promote platelet aggregation or plasma coagulation in vitro. Thromb Res. 2004; 114:179-84.

4. Son KH, Chung JH, Sun K, Son HS. Cardiac perforation and tricuspid regurgitation as a complication of percutaneous vertebroplasty. Eur J Cardiothorac Surg. 2008;33:508-9.

5. Lim KJ, Yoon SZ, Jeon YS, Bahk JH, Kim CS, Lee JH, et al. An intraatrial thrombus and pulmonary thromboembolism as a late complication of percutaneous vertebroplasty. Anesth Analg. 2007;104:924-6.

\title{
Attenuation of bone morphogenetic protein receptor type 2 expression in the pulmonary arteries of patients with failed Fontan circulation
}

\author{
Hidekazu Ishida, MD, Shigetoyo Kogaki, MD, Kunihiko Takahashi, MD, PhD, and \\ Keiichi Ozono, MD, PhD, Osaka, Japan
}

The Fontan procedure is a standard treatment for complex congenital heart defects when biventricular repair cannot be performed. Although the outcomes of the Fontan procedure have been improved recently, some patients still have failure of the Fontan circulation, with consequences such as exercise intolerance, protein-losing enteropathy, and plastic bronchitis, which is at least partially attributable to high

From the Department of Pediatrics, Osaka University Graduate School of Medicine, Osaka, Japan.

Disclosures: Authors have nothing to disclose with regard to commercial support. Received for publication May 17, 2011; revisions received Sept 20, 2011; accepted for publication Dec 8, 2011; available ahead of print Feb 17, 2012.

Address for reprints: Shigetoyo Kogaki, MD, 2-2 Yamadaoka, Suita, Osaka 565-

0871, Japan (E-mail: skogaki@ped.med.osaka-u.ac.jp).

J Thorac Cardiovasc Surg 2012;143:e24-6

$0022-5223 / \$ 36.00$

Copyright $(c) 2012$ by The American Association for Thoracic Surgery

doi:10.1016/j.jtcvs.2011.12.064 pulmonary vascular resistance. We previously reported that endothelin-1 and its receptors were overexpressed in the pulmonary arteries of patients with failed Fontan circulation ${ }^{1}$; however, the pathobiology of pulmonary arterial remodeling in these patients remains unclear.

Because heterozygous mutations in bone morphogenetic protein receptor type 2 (BMPR2) have been identified in patients with familial and idiopathic pulmonary arterial hypertension, bone morphogenetic protein (BMP) and its signal transduction were thought to be critical in pulmonary arterial hypertension pathogenesis. ${ }^{2}$ Bone morphogenetic protein signaling plays a pivotal role in regulating cell proliferation, differentiation, and apoptosis. Impairment of BMPR2 function thus may cause pulmonary vascular remodeling and increase pulmonary vascular resistance. Previous studies have shown that reduced BMPR2 expression is also associated with secondary pulmonary arterial hypertension. Our study is the first to demonstrate attenuation of

TABLE 1. Clinical characteristics and hemodynamic data of the patients

\begin{tabular}{|c|c|c|c|c|c|c|c|c|c|c|c|c|}
\hline \multirow{2}{*}{$\begin{array}{c}\text { Patient } \\
\text { no. }\end{array}$} & \multirow[b]{2}{*}{ Sex } & \multirow[b]{2}{*}{ Diagnosis } & \multicolumn{2}{|c|}{ Fontan } & \multicolumn{2}{|c|}{ Death } & \multicolumn{2}{|c|}{ MPAP (mm Hg) } & \multicolumn{2}{|c|}{ TPG (mm Hg) } & \multicolumn{2}{|c|}{$\operatorname{PVR}\left(\mathrm{U} / \mathrm{m}^{2}\right)$} \\
\hline & & & Age (y) & Type & Age (y) & Cause & Pre & Post & Pre & Post & Pre & Post \\
\hline 1 & $\mathrm{~F}$ & SV & 9 & APC & 20 & $\mathrm{HF}$ & 12 & 11 & 6 & 3 & 1.0 & 2.3 \\
\hline 2 & M & SV & 16 & LT & 18 & FF & 13 & 26 & 5 & 14 & 1.6 & 3.8 \\
\hline 3 & $\mathrm{~F}$ & PAIVS & 8 & APC & 13 & FF & 12 & 16 & 6 & 7 & 0.9 & 3.6 \\
\hline 4 & M & SV & 8 & APC & 15 & FF & 9 & 13 & 5 & 9 & 1.2 & 3.8 \\
\hline 5 & $\mathrm{~F}$ & DORV & 3 & LT & 13 & $\mathrm{HF}$ & 15 & 22 & 4 & 5 & 3.0 & 3.1 \\
\hline 6 & M & SV & 3 & LT & 4 & Inf & 10 & 15 & 6 & 5 & 2.0 & NA \\
\hline 7 & M & SV & 3 & LT & 3 & FF & 14 & 18 & 6 & 16 & 1.4 & NA \\
\hline 8 & $\mathrm{~F}$ & DORV & 2 & ECC & 3 & $\mathrm{HF}$ & 18 & 13 & 5 & 4 & 2.2 & 1.9 \\
\hline 9 & $\mathrm{~F}$ & $\mathrm{TA}$ & 7 & APC & 16 & SD & 11 & NA & 5 & NA & 1.0 & NA \\
\hline 10 & $\mathrm{M}$ & SV & 4 & ECC & 7 & $\mathrm{SD}$ & 10 & 9 & 7 & 5 & 0.8 & 2.6 \\
\hline
\end{tabular}

MPAP, Mean pulmonary arterial pressure; TPG, transpulmonary gradient; PVR, pulmonary vascular resistance; Pre, before Fontan operation; Post, after Fontan operation; SV, single ventricle; $A P C$, atriopulmonary connection; HF, heart failure; $L T$, lateral tunnel; $F F$, Fontan failure; PAIVS, pulmonary atresia with intact ventricular septum; $D O R V$, double-outlet right ventricle; Inf, infection; $N A$, not available; $E C C$, extracardiac conduit; $T A$, tricuspid atresia; $S D$, sudden cardiac death. 

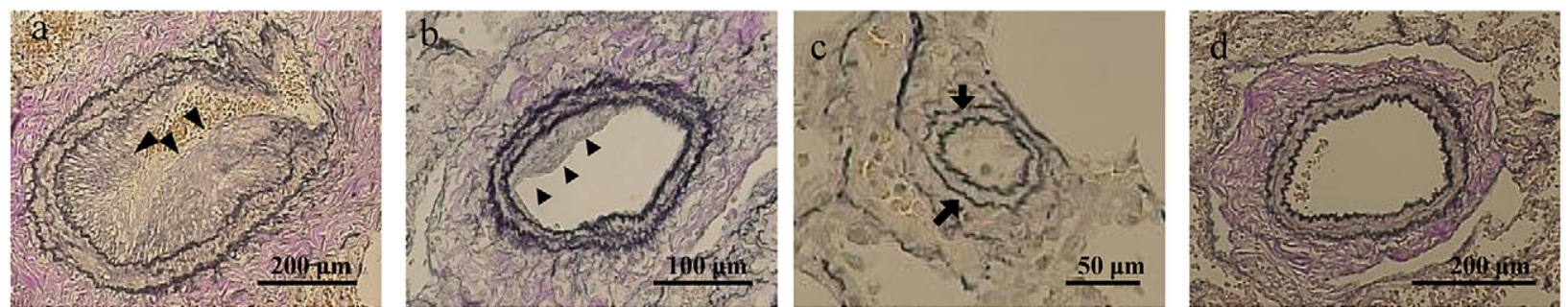

A
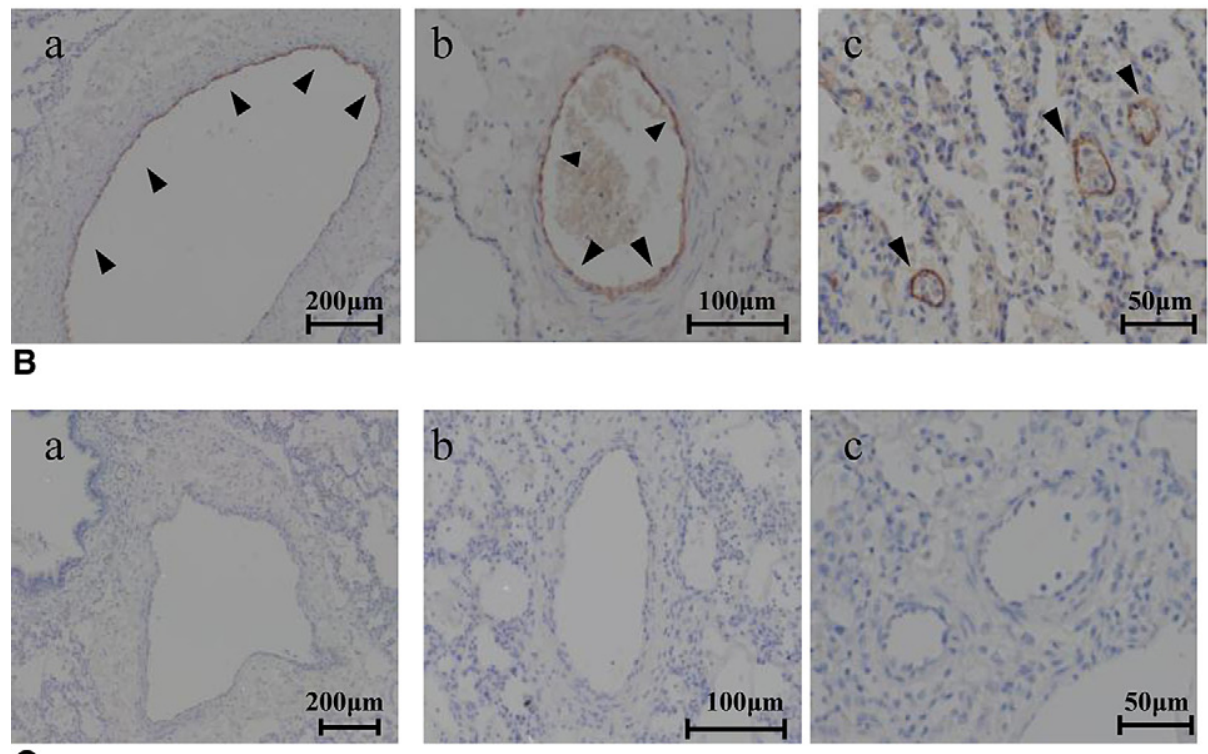

C

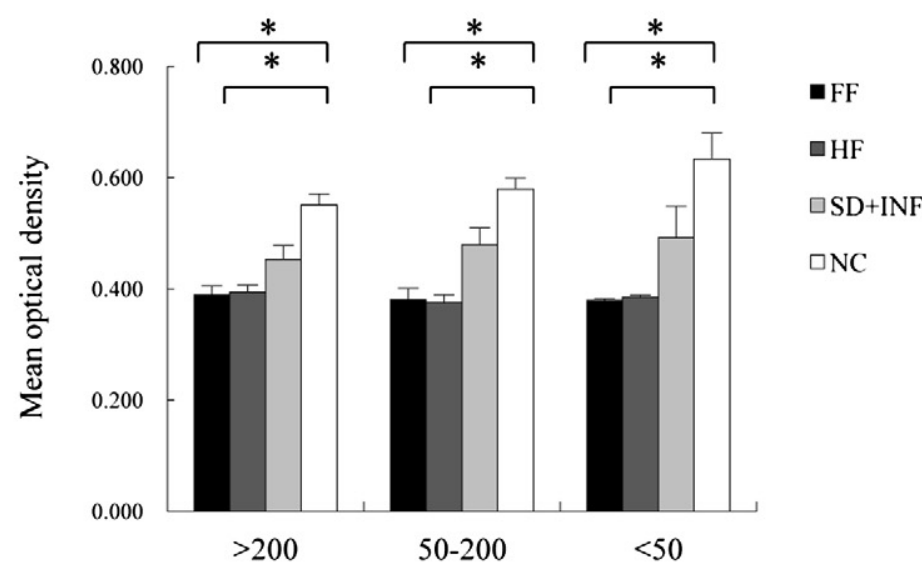

\section{D}

Vascular external diameter $(\mu \mathrm{m})$

$E$

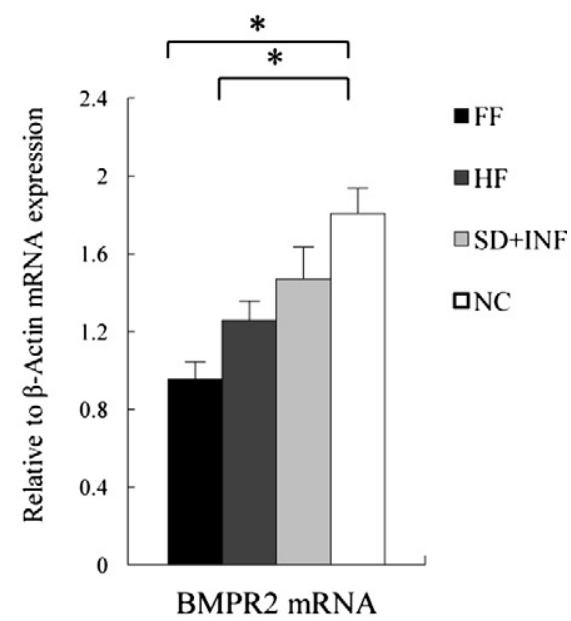

FIGURE 1. Immunohistochemical and quantitative real-time polymerase chain reaction analyses of bone morphogenetic protein receptor type 2 (BMPR2) expressions in pulmonary arteries of patients who died after the Fontan procedure. A, Elastica-van Gieson stains of the pulmonary arteries of patients with failed Fontan circulations show severe intimal (arrowheads) and medial (arrows) hypertrophy $(a, b$, and $c$ ) relative to healthy control samples $(d)$. B, In healthy control subjects, bone morphogenetic protein receptor type 2 is strongly expressed on endothelium in both proximal and distal pulmonary arteries (arrowheads). C, In contrast, in patients with failed Fontan circulations, bone morphogenetic protein receptor type 2 expression is significantly decreased. D, The result of computational mean optical density analyses of pulmonary bone morphogenetic protein receptor type 2 expression. bone morphogenetic protein receptor type 2 expression levels are significantly lower in the failed Fontan circulation $(F F)$ and heart failure $(H F)$ groups than in the control $(N C)$ group. Asterisk indicates $P<.01$. E, $S D+I N F$, Sudden cardiac death plus infectious cause of death. The quantitative real-time polymerase chain reaction analyses of bone morphogenetic protein receptor type 2 messenger RNA (mRNA) expressions in the lung tissues. Asterisk indicates $P<.01$. 
BMPR2 expression in the pulmonary arteries of patients with failed Fontan circulations.

\section{MATERIALS AND METHODS}

Ten autopsy lung tissue samples were obtained from patients who had died after the Fontan procedure between 1992 and 2000. We divided the patients into 3 subgroups according to their clinical courses and hemodynamic data: failed Fontan circulation (preserved ventricular function with high transpulmonary gradient, $\mathrm{n}=4$ ), heart failure (severe ventricular dysfunction with relatively low transpulmonary gradient, $\mathrm{n}=3$ ), and sudden cardiac death or death from infection $(n=3)$. Age-matched subjects without any cardiovascular disease $(n=4)$ were included as a control group. Table 1 shows the clinical features and hemodynamic data of the patients. The hemodynamic parameters were extracted from the catheterization data just before the Fontan procedure and the latest catheterization data after the Fontan procedure. Histologic, immunohistochemical, and quantitative real-time polymerase chain reaction analyses were performed to determine the pulmonary BMPR2 expressions in the lung tissues. Results are expressed as mean \pm SE. Statistical analyses were performed with TukeyKramer multiple comparison tests.

\section{RESULTS}

The small muscular arteries of the patients with failed Fontan circulations showed not only medial hypertrophy but also severe intimal thickening (Figure 1, A). The percentage wall thicknesses of the proximal $(>200 \mu \mathrm{m})$ and intra-acinar arteries (50-200 $\mu \mathrm{m})$ were significantly higher in the failed Fontan circulation group than in the control and sudden cardiac death plus infection groups (for $>200-\mu \mathrm{m}$ arteries, failed Fontan, $27.1 \% \pm 3.4 \%$; heart failure, $21.9 \% \pm 2.6 \%$; sudden cardiac death plus infection, $17.4 \% \pm 2.4 \%$; control, $14.4 \% \pm 2.0 \%$; for 50 - to 200 $\mu \mathrm{m}$ arteries, failed Fontan, $39.6 \% \pm 6.4 \%$; heart failure, $25.8 \% \pm 1.5 \%$; sudden cardiac death plus infection, $16.7 \% \pm 4.1 \%$; control, $14.2 \% \pm 2.5 \%$ ).

The endothelial cells of normal pulmonary arteries showed strong positive immunostaining for BMPR2, whereas the vascular smooth muscle cells showed only weak staining (Figure 1,B). The endothelial BMPR2 expression was significantly lower in the patients with failed Fontan circulations than in the control patients (Figure 1,C). The mean optical density of BMPR2 immunostaining of arteries with different sizes, quantified by computational analyses, showed that the BMPR2 expression levels were significantly lower in the failed Fontan circulation and heart failure groups than in the control group (Figure 1,D).

BMPR2 messenger RNA expression was significantly lower in the failed Fontan circulation and heart failure groups than in the control group (Figure 1,E). This result was consistent with the findings of the immunohistochemical staining, suggesting a significant reduction in the expression of BMPR2 messenger RNA in the pulmonary arteries of the patients with failed Fontan circulations.

\section{DISCUSSION}

This is the first study that has shown a significant reduction in BMPR2 expression in patients with failed Fontan circulations. Bone morphogenetic protein signaling regulates endothelial cell survival and vascular smooth muscle cell apoptosis. ${ }^{2}$ A reduced pulmonary BMPR2 level thus may induce pulmonary endothelial dysfunction and extensive proliferation of pulmonary vascular smooth muscle cells, resulting in vascular remodeling (Figure 1, $A$ ) and an elevation in pulmonary vascular resistance. Although the mechanisms of downregulation of BMPR2 expression in patients with failed Fontan circulation are unclear, hypoxia and cytokines have been suggested to cause BMPR2 downregulation. ${ }^{3,4}$ An abnormal ventilation-perfusion distribution has also been reported after the Fontan operation. ${ }^{5}$ We therefore speculate that hypoxia in the local pulmonary areas, some cytokines induced by local inflammation or thrombosis, or both may be involved in the attenuation of BMPR2 expression. When the Fontan circulation begins to deteriorate in patients, these factors (hypoxia, cytokines, and inflammation) can downregulate BMPR2 expression. BMPR2 downregulation may be a key pathologic factor in failure of Fontan circulation. We think that the bone morphogenetic protein pathway is a potential therapeutic target in the treatment for failing Fontan circulation, as it is for pulmonary arterial hypertension.

\section{References}

1. Ishida H, Kogaki S, Ichimori H, Narita J, Nawa N, Ueno T, et al. Overexpression of endothelin-1 and endothelin receptors in the pulmonary arteries of failed Fontan patients. Int J Cardiol. Epub 2011 Feb 26.

2. Archer SL, Weir EK, Wilkins MR. Basic science of pulmonary arterial hypertension for clinicians: new concepts and experimental therapies. Circulation. 2010; 121:2045-66.

3. Takahashi K, Kogaki S, Matsushita T, Nasuno S, Kurotobi S, Ozono K. Hypoxia induces alteration of bone morphogenetic protein receptor signaling in pulmonary artery endothelial cell. Pediatr Res. 2007;61:392-7.

4. Brock M, Trenkmann M, Gay RE, Michel BA, Gay S, Fischler M, et al. Interleukin-6 modulates the expression of the bone morphogenic protein receptor type II through a novel STAT3-microRNA cluster 17/92 pathway. Circ Res. 2009;104: 1184-91.

5. Matsushita T, Matsuda H, Ogawa M, Ohno K, Sano T, Nakano S, et al. Assessment of the intrapulmonary ventilation-perfusion distribution after the Fontan procedure for complex cardiac anomalies: relation to pulmonary hemodynamics. J Am Coll Cardiol. 1990;15:842-8. 